\title{
A randomized clinical trial of ascorbic acid in open abdominal aortic aneurysm repair
}

\author{
Martin J Duffy ${ }^{1,2}$, Cecilia M O'Kane ${ }^{2}$, Michael Stevenson ${ }^{3}$, lan S Young ${ }^{3}$, Denis W Harkin ${ }^{4}$, Brian A Mullan ${ }^{1,2}$ \\ and Daniel F McAuley ${ }^{1,2^{*}}$
}

\author{
* Correspondence: \\ d.f.mcauley@qub.ac.uk \\ ${ }^{1}$ Regional Intensive Care Unit, Royal \\ Victoria Hospital, Belfast, UK \\ ${ }^{2}$ Centre for Infection and Immunity, \\ The Queen's University Belfast, First \\ Floor, Health Sciences Building, 97 \\ Lisburn Road, Belfast BT9 7BL, UK \\ Full list of author information is \\ available at the end of the article
}

\begin{abstract}
Background: Open AAA repair is associated with ischaemia-reperfusion injury where systemic inflammation and endothelial dysfunction can lead to multiple organ injury including acute lung injury. Oxidative stress plays a role that may be inhibited by ascorbic acid.
\end{abstract}

Methods: A double blind, allocation concealed, randomized placebo-controlled trial was performed to test the hypothesis that a single bolus dose (2g) of intra-operative parenteral ascorbic acid would attenuate biomarkers of ischaemia-reperfusion injury in patients undergoing elective open AAA repair.

Results: Thirty one patients completed the study; 18 received placebo and 13 ascorbic acid. Groups were comparable demographically. Open AAA repair caused an increase in urinary Albumin:Creatinine Ratio (ACR) as well as plasma IL-6 and IL-8. There was a decrease in exhaled breath $\mathrm{pH}$ and oxygenation. Lipid hydroperoxides were significantly higher in the ascorbic acid group following open AAA repair. There were no other differences between the ascorbic acid or placebo groups up to 4 hours after removal of the aortic clamping.

Conclusions: Open AAA repair caused an increase in markers of systemic endothelial damage and systemic inflammation. Administration of $2 \mathrm{~g}$ parenteral ascorbic acid did not attenuate this response and with higher levels of lipid hydroperoxides postoperatively a pro-oxidant effect could not be excluded.

Trial registration: ISRCTN27369400

Keywords: Ascorbic Acid; Ichaemia-Reperfusion injury; Abdominal aortic aneurysm; Perioperative anaesthesia; Perioperative critical care

\section{Background}

Open Abdominal Aortic Aneurysm (AAA) repair necessitates the use of an aortic cross-clamp which causes an ischaemia-reperfusion injury to remote tissues which can lead to multiple organ dysfunction syndrome (MODS) including acute lung injury (ALI) and death [1].

Ischaemia-reperfusion injury is associated with an increase in oxidative stress through the accumulation of reactive oxygen species (ROS) which can up-regulate proinflammatory pathways contributing to remote organ dysfunction [2,3]. Lipid peroxidation is central in oxidative stress and can be measured using end products [4]. Ischaemia leads to endothelial activation with increased expression of endothelial adhesion molecules [5].

\section{Springer}

(c) 2015 Duffy et al. This is an Open Access article distributed under the terms of the Creative Commons Attribution License (http:// creativecommons.org/licenses/by/4.0), which permits unrestricted use, distribution, and reproduction in any medium, provided the original work is properly credited. 
Reperfusion enhances this response and is associated with up-regulation of plasma cytokines [6] and increased leucocyte interaction [7]. Increased urinary albumin:creatinine ratio (ACR) has been associated with impaired endothelial-dependent vasodilation [8], a surrogate measure of endothelial dysfunction [9]. There is evidence of systemic endothelial dysfunction as measured by urinary albumin:creatinine ratio (ACR) in patients undergoing open AAA repair [10] correlating with outcome from ALI in this setting [11,12]. In patients undergoing open AAA repair a rise in ACR measured 4 hours following induction of anaesthesia predicted those at risk of post-operative pulmonary dysfunction [13].

Pulse Wave Analysis (PWA) provides a bedside measure of systemic endothelial function and has been shown to independently predict mortality in the critically ill [14]. Pulmonary dead-space fraction is increased in the acute respiratory distress syndrome (ARDS) and may reflect the extent of pulmonary endothelial dysfunction [15].

Ascorbic acid can act as a reactive oxygen species (ROS) scavenger [16,17]. Low ascorbic acid levels have been described in humans subjected to ischaemia-reperfusion injury during cardiac surgery $[18,19]$ and are associated with acute inflammation [20]. Ascorbic acid attenuates endothelial dysfunction in animal models of acute lung injury (ALI) [21] a condition characterized by uncontrolled inflammation [22]. Ascorbic acid can improve endothelial function [23] by inhibiting apoptosis [24], and preserving endothelial barrier function [25]. As a scavenger it reduces oxidative uncoupling of endothelial nitric oxide synthase (eNOS) leading to further ROS production [26,27]. The hypothesis in this study was that an intra-operative bolus dose $(2 \mathrm{~g})$ of parenteral ascorbic acid may attenuate markers of oxidative stress, inflammation and endothelial dysfunction caused by open AAA repair.

\section{Methods}

This was a single centre, double blind allocation concealed, randomized placebocontrolled trial. The protocol was approved by the local institution, the UK Medicines and Healthcare products Regulatory Agency and the regional ethics committee. Written informed consent was obtained from each participant prior to study commencement. The trial is registered with www.isrctn.com (ISRCTN27369400).

The study was performed at the Royal Victoria Hospital, Belfast, a tertiary care teaching hospital. Adults undergoing elective open AAA repair were eligible for enrollment. Exclusion criteria were age less than 18 years old, a history of hyperoxaluria or glucose6-phosphate dehydrogenase deficiency, prior antioxidant therapy, known allergy to ascorbic acid or to anaesthetic agents specified in anaesthetic protocol, participation in another intervention trial within 30 days or a lack of consent.

Patients were randomly assigned to receive intraoperative intravenous ascorbic acid $2 \mathrm{~g}$ in $250 \mathrm{ml} 0.9 \%$ saline or $250 \mathrm{ml} 0.9 \%$ saline placebo over 15 minutes following induction of anaesthesia. Block randomization was performed by an independent statistician. The randomization assignments were concealed in sealed, tamper-proof envelopes that were opened sequentially by an independent pharmacist. When an eligible subject was recruited, the pharmacist allocated the subject to the designated treatment group, maintaining blinding. Ascorbic acid and $0.9 \%$ saline were prepared by the independent pharmacist and had an identical appearance. All staff and participants were blinded to treatment allocation. 


\section{Data collection}

Baseline demographic data were collected including medical history. All participants underwent transperitoneal open AAA repair via midline laparotomy. Anaesthesia was provided via a standardized technique.

A summary of events and measurements performed is shown in Figure 1.

\section{Measurements}

Plasma and serum samples were obtained from arterial blood samples taken from the indwelling arterial catheter. Blood samples were centrifuged at $2000 \mathrm{rpm}$ for $10 \mathrm{mi}$ nutes at $10^{\circ} \mathrm{C}$ and then samples were frozen at $-80^{\circ} \mathrm{C}$ until analysis. Urine samples were collected and frozen at $-80^{\circ} \mathrm{C}$ until analysis.

Plasma Von Willebrand Factor (vWF) level was measured by ELISA as previously described [11]. Soluble forms of Intercellular adhesion molecule (sICAM)-1, vascular cell adhesion molecule (sVCAM)-1, endothelial (sE)-Selectin and platelet (sP)-Selectin were measured using a Fluorokine ${ }^{\oplus}$ MAP multiplex kit (R\&D Systems, Minneapolis, MN, USA) with a BioRad BioPlex ${ }^{\mathrm{TM}}$ analyser (Luminex Corp., Austin, TX, USA). Interleukins IL-6 and IL-8 were measured using a cytometric bead array (R\&D Systems, Abingdon, UK) as previously described [28]. Serum highly sensitive C Reactive Protein (hsCRP) analysis was performed using the Quantex CRP ultra sensitive quantitative system (ILab Chemistry Systems, Instrumentation Laboratory Company, Lexington, Mass). Serum aqueous phase lipid hydroperoxides were measured using the ferrous iron/xylenol orange (FOX) assay as previously described [29]. Plasma 8-iso-Prostaglandin F2 $\alpha$ was measured using a direct enzyme immunoassay kit (Assay Designs Inc., Ann Arobor, Michigan, USA) with a BioRad BioPlex ${ }^{\mathrm{Tm}}$ analyser (Luminex Corp., Austin, TX, USA). To measure plasma ascorbic acid, plasma was mixed with $5 \%$ meta-phosphoric acid (MPA) to stabilise ascorbic acid and then measured on a Cobas FARA centrifugal analyser with a fluorescent attachment according to Vuilleumier \& Keck [30]. To determine urinary ACR, albumin was measured in urine using a commercially available immunoturbidimetric assay containing antibody specific for human albumin (Randox Laboratories Ltd. Crumlin, Co. Antrim, UK). Creatinine was measured using a modified Jaffe method as previously described (Roche Diagnostics, IN, USA) [31].

PWA was used to assess systemic endothelial function as previously described [14]. This was performed with the SphygmoCor Mx System (AtCor Medical, Sydney, Australia). An indwelling 20G radial arterial catheter was used to obtain a calibrated peripheral arterial pressure waveform. The central aortic waveform was derived from the peripheral arterial waveform using a validated transfer function [32,33]. Aortic

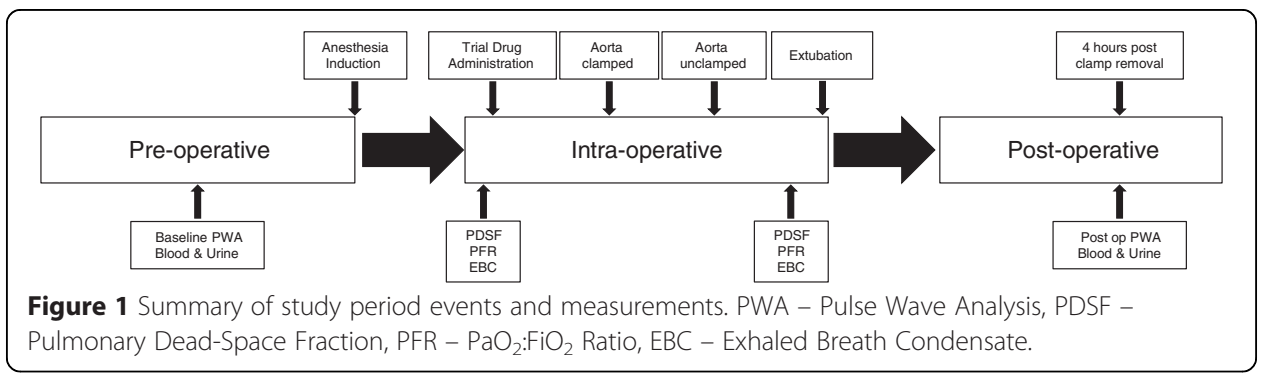


augmentation is defined as the difference between the first systolic peak (caused by left ventricular contraction) and second systolic peak (caused by wave reflection) and the augmentation index (AIx) is this difference expressed as a percentage of the central pulse pressure. AIx is calculated and corrected to a heart rate to 75 beats $/ \mathrm{min}$. The AIx following nebulised salbutamol $2.5 \mathrm{mg}$ measures endothelium dependent vasodilation (EDV) [34].

Pulmonary Dead-Space Fraction (Vd/Vt) was measured using volumetric capnography utilizing the NICO2 Monitor (Philips Respironics UK Ltd., Tangmere, UK) to calculate the partial pressure of expired $\mathrm{CO}_{2}$. This is then used in the Enghoff modification of the Bohr equation [35]. This method has been validated in a cohort of patients with acute lung injury [36].

Exhaled Breath Condensate (EBC) $\mathrm{pH}$ as a measure of alveolar neutrophilic inflammation was measured in EBC collected using an RTube ${ }^{\mathrm{ma}}$ (Respiratory Research, Austin, TX, USA) as previously described [37]. Exhaled breath condensate $\mathrm{pH}$ was measured using an Orion 9803BN micro $\mathrm{pH}$ electrode and digital $\mathrm{pH}$ meter (Thermo Scientific, Waltham, MA, USA) immediately after collection.

\section{Statistics}

Proportions were used as descriptive statistics for categorical variables. Mean (standard deviation) or median (interquartile range) were used as appropriate after testing for normality with the Kolmogorov-Smirnov test. Between group categorical variables were compared using Fishers exact test and continuous variables with an unpaired Student's $t$-test or Mann-Whitney $U$ test as appropriate. Comparison of variables before and after open AAA repair was made using a paired Student's $t$-test or Wilcoxon matched pairs test as appropriate. Statistical analysis was performed and graphs generated using Prism 5 for Mac OS X, version 5.0b (GraphPad Software Inc.). A P value of $<0.05$ was considered significant.

\section{Power calculation}

The sample size calculation was determined using data from a previous study examining plasma vWF concentration in elective open AAA repair patients [12]. Based on these data, mean (standard deviation) vWF concentrations of 175(56) and 125(40) U/dl were assumed for patients receiving placebo and ascorbic acid respectively. On this basis 31 patients were required to complete the study. On the basis of assumed unequal variance between the groups, 18 patients were allocated to receive placebo and 13 to receive ascorbic acid. This provided $80 \%$ power to detect a statistical difference if the true difference was as suggested above. This calculation assumed that a two-tailed $t$-test at a $5 \%$ significance level was applied.

\section{Results}

Forty three patients were screened over an 18 month period. Twelve patients were excluded. Thirty-one participants received study drug, completed the study and were included in the analysis. Thirteen patients received ascorbic acid and 18 received placebo (Figure 2). 


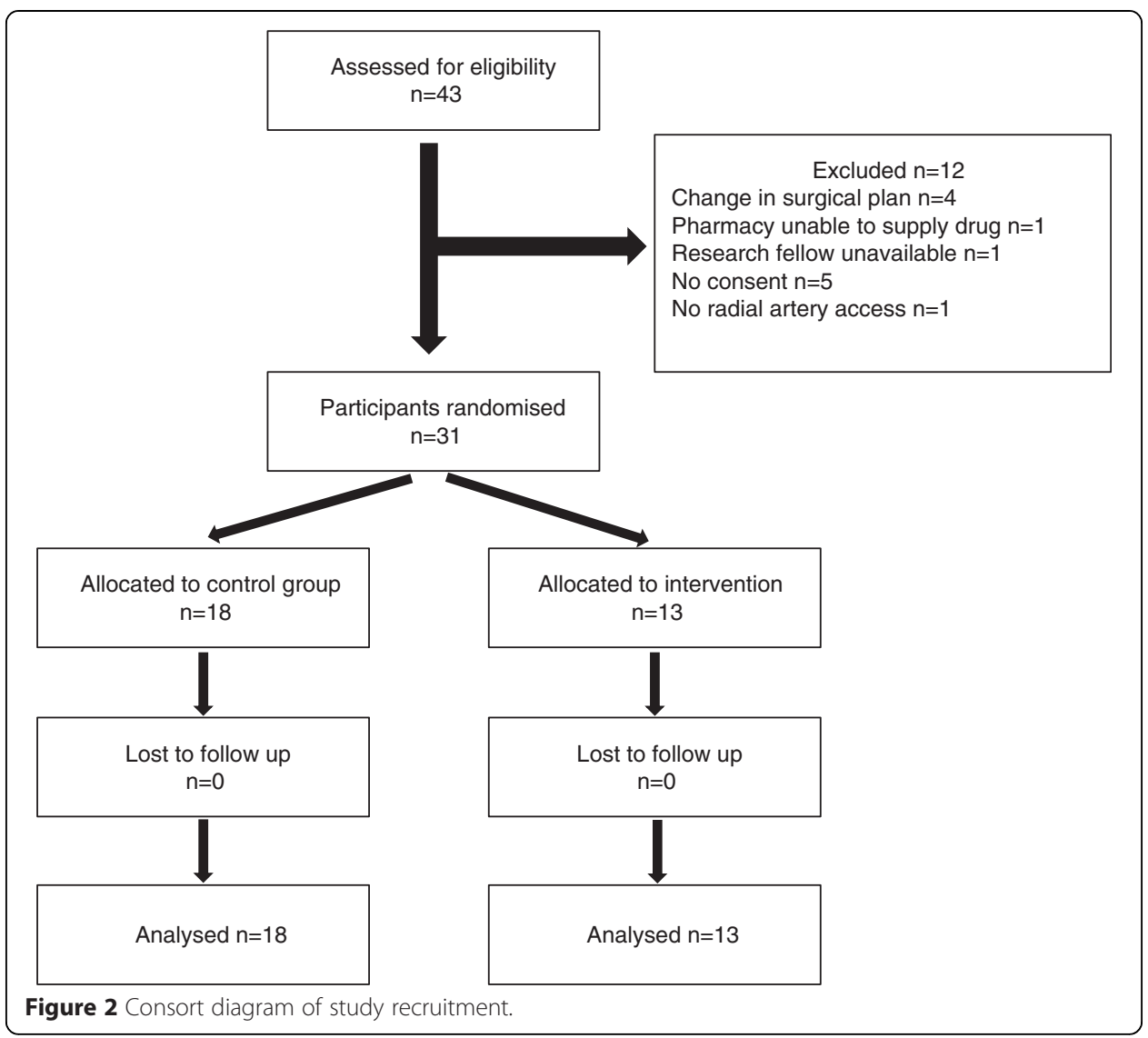

Baseline characteristics were similar in both groups. The duration of ischaemic injury caused by the aortic clamp was similar between groups (Table 1). Mean arterial pressure fell intra-operatively from 101 (17) $\mathrm{mmHg}$ to 85 (15) $\mathrm{mmHg}$ in the ascorbic acid group $(\mathrm{p}=0.03)$ and from $101(16) \mathrm{mmHg}$ to $82(15) \mathrm{mmHg}$ in the placebo group $(\mathrm{p}<0.001)$ but there were no differences between groups either pre- or postoperatively. Ascorbic acid levels measured four hours following removal of the aortic clamp were higher in the ascorbic acid group compared to placebo $(104.4(84.8,132.7)$ umoll-1 vs $18.2(6.2,34.5) \mu$ moll- $1, \mathrm{p}<0.001)$.

\section{Effects of ascorbic acid on endothelial function}

Plasma VWF levels were similar between groups both before and after open AAA repair. Similarly there were no differences in EDV between groups either pre- or post-operatively (Table 2). Urinary ACR was significantly higher in both the placebo $(\mathrm{p}<0.001)$ and ascorbic acid ( $p=0.01)$ groups after AAA repair, however there were no differences between the groups (Figure 3). There were no significant changes in pulmonary deadspace following open AAA repair (Table 2).

\section{Effects of ascorbic acid on soluble adhesion molecules}

Plasma sICAM-1 fell within both the placebo $(\mathrm{p}<0.001)$ and ascorbic acid $(\mathrm{p}=0.005)$ groups after open AAA repair, There was no difference between placebo and ascorbic 
Table 1 Demographic, historical and pre-operative physiological parameters

\begin{tabular}{|c|c|c|}
\hline & $\begin{array}{l}\text { Placebo group } \\
\mathrm{n}=18 \\
\text { Mean (SD), Median } \\
\text { (IQR) or } \mathrm{n}(\%)\end{array}$ & $\begin{array}{l}\text { Ascorbate group } \\
\mathrm{n}=13 \\
\text { Mean (SD), Median } \\
\text { (IQR) or } \mathrm{n}(\%)\end{array}$ \\
\hline \multicolumn{3}{|l|}{ Demographics } \\
\hline Age (years) & $70.4(7.4)$ & $73.2(5.9)$ \\
\hline Height (m) & $1.71(0.09)$ & $1.71(0.05)$ \\
\hline Weight (kg) & $77.1(11.1)$ & $78.2(7.7)$ \\
\hline BMI $\left(\mathrm{kgm}^{-2}\right)$ & $26.4(3.3)$ & $26.8(2.8)$ \\
\hline Gender (\% male) & $17(94 \%)$ & $11(85 \%)$ \\
\hline \multicolumn{3}{|l|}{ Past medical history } \\
\hline IHD & $8(44 \%)$ & $4(31 \%)$ \\
\hline Atrial Fibrillation & $0(0 \%)$ & $2(15 \%)$ \\
\hline Hypertension & $16(89 \%)$ & $12(92 \%)$ \\
\hline Cerebrovascular Disease & $1(6 \%)$ & $1(8 \%)$ \\
\hline \multicolumn{3}{|l|}{ Cardiovascular risk factors } \\
\hline Smoking & $4(22 \%)$ & $5(38 \%)$ \\
\hline Hypercholesterolaemia & $10(56 \%)$ & $6(46 \%)$ \\
\hline Hypertension & $16(89 \%)$ & $12(92 \%)$ \\
\hline Diabetes & $1(6 \%)$ & $0(0 \%)$ \\
\hline \multicolumn{3}{|l|}{ Drug history } \\
\hline Statin & $12(67 \%)$ & $9(69 \%)$ \\
\hline ACE Inhibitors & $5(28 \%)$ & $3(23 \%)$ \\
\hline$\beta$ Blockers & 7 (39\%) & $6(46 \%)$ \\
\hline Diuretics & $2(11 \%)$ & $3(23 \%)$ \\
\hline Anticoagulants & $5(28 \%)$ & $5(38 \%)$ \\
\hline \multicolumn{3}{|c|}{ Baseline physiological parameters } \\
\hline Respiratory Rate $\left(\mathrm{min}^{-1}\right)$ & $14(12,15)$ & $12(12,15)$ \\
\hline Temperature $\left({ }^{\circ} \mathrm{C}\right)$ & $36.6(0.33)$ & $36.8(0.38)$ \\
\hline Heart Rate $\left(\min ^{-1}\right)$ & $63(10.3)$ & $60(13.7)$ \\
\hline Peripheral SBP (mmHg) & $145.2(24.9)$ & $150.5(29.6)$ \\
\hline Peripheral DBP (mmHg) & $77(12.4)$ & $76(11.7)$ \\
\hline \multicolumn{3}{|c|}{ Haematological and biochemical indices } \\
\hline Haemoglobin $\left(\mathrm{gdl}^{-1}\right)$ & $13.7(1.2)$ & $13.7(1.1)$ \\
\hline Leucocyte Count $\left(\times 10^{9} \mathrm{ml}^{-1}\right)$ & $7.3(1.7)$ & $7.3(1.8)$ \\
\hline Platelet Count $\left(\times 10^{9} \mathrm{ml}^{-1}\right)$ & $201(54)$ & $211(64)$ \\
\hline Urea $\left(m m o l^{-1}\right)$ & $7.8(2.1)$ & $6.7(1.8)$ \\
\hline Creatinine $\left(\mu \mathrm{mol} \|^{-1}\right)$ & $96(31)$ & $101(30)$ \\
\hline \multicolumn{3}{|l|}{ Surgical details } \\
\hline Ischaemic Time (mins) & $60.5(16.9)$ & $64.6(17.6)$ \\
\hline
\end{tabular}

SD, Standard Deviation, IQR, Interquartile Range, BMI, Body Mass Index, SBP, Systolic Blood Pressure, DBP, Diastolic Blood Pressure, IHD, Ischaemic Heart Disease, ACE, Angiotensin Converting Enzyme.

acid groups pre-operatively ( $\mathrm{p}=0.1$ ) however plasma sICAM-1 was higher in the ascorbic acid group post-operatively ( $\mathrm{p}=0.03$ vs placebo, Figure $4 \mathrm{~A}$ ). Plasma sVCAM-1 was similar pre and post open AAA repair in both groups and there was no difference between groups (Figure 4B). Plasma sE-Selectin fell post-operatively within both the 
Table 2 Comparison of biomarkers in ascorbic acid and placebo groups pre- and post-operatively

\begin{tabular}{|c|c|c|c|c|c|c|}
\hline & \multicolumn{3}{|c|}{ Pre operative parameters } & \multicolumn{3}{|c|}{ Post operative parameters } \\
\hline & $\begin{array}{l}\text { Placebo } \\
\text { group }\end{array}$ & $\begin{array}{l}\text { Ascorbate } \\
\text { group }\end{array}$ & p-value & $\begin{array}{l}\text { Placebo } \\
\text { group }\end{array}$ & $\begin{array}{l}\text { Ascorbate } \\
\text { group }\end{array}$ & p-value \\
\hline & $\mathrm{n}=18$ & $n=13$ & & $\mathrm{n}=18$ & $n=13$ & \\
\hline & Mean (SD), & Mean (SD), & & Mean (SD), & Mean (SD), & \\
\hline & Median (IQR) & Median (IQR) & & Median (IQR) & Median (IQR) & \\
\hline \multicolumn{7}{|l|}{ Endothelial function } \\
\hline VWF (\% Control) & $141(61)$ & $139(60)$ & 0.92 & $158(78)$ & $169(65)$ & 0.68 \\
\hline EDV (\%) & $3.5(1.8,5.3)$ & $3.0(1.5,5.5)$ & 0.42 & $6.0(2.5,8.5)$ & $4.0(2.0,6.0)$ & 0.32 \\
\hline $\mathrm{Vd} / \mathrm{Nt}$ & $0.56(0.06)$ & $0.54(0.05)$ & 0.53 & $0.56(0.06)$ & $0.54(0.06)$ & 0.74 \\
\hline \multicolumn{7}{|c|}{ Systemic and pulmonary inflammatory mediators } \\
\hline Serum hsCRP $\left(\mathrm{mgL}^{-1}\right)$ & $2.14(0.97,5.75)$ & $1.83(1.15,4.49)$ & 0.95 & $2.85(1.45,4.63)$ & $1.96(1.13,4.23)$ & 0.27 \\
\hline Arterial pH & $7.38(0.04)$ & $7.40(0.05)$ & 0.43 & $7.32(0.08)$ & $7.29(0.06)$ & 0.20 \\
\hline \multicolumn{7}{|l|}{ Pulmonary function } \\
\hline $\mathrm{PaO}_{2}: \mathrm{FiO}_{2}$ ratio $(\mathrm{kPa})$ & $59.6(47.8,81.1)$ & $59.6(46.5,97.7)$ & 0.44 & $45.3(28.3,49.4)$ & $42.5(32.7,51.4)$ & 0.79 \\
\hline
\end{tabular}

SD, Standard Deviation, IQR, Interquartile Range, EDV, Endothelium-dependent vasodilatation, vWF, von Willebrand Factor, Vd/Vt, Pulmonary Deadspace Fraction, EBC, Exhaled Breath Condensate, CRP, C Reactive Protein.

placebo $(\mathrm{p}<0.001)$ and ascorbic acid $(\mathrm{p}=0.002)$ groups, although there was no difference between the groups (Figure 4C). Plasma sP-Selectin fell post-operatively within the placebo $(\mathrm{p}=0.0001)$ but not the ascorbic acid $(\mathrm{p}=0.41)$ groups, although there was no difference between the groups (Figure 4D).

\section{Effects of ascorbic acid on systemic and pulmonary markers of inflammation}

Plasma CRP was similar pre and post open AAA repair in both groups and there was no difference between groups (Table 2). Plasma IL-6 increased during the study period in the placebo $(\mathrm{p}<0.001)$ and ascorbic acid $(\mathrm{p}<0.001)$ groups although there was no difference between the groups (Figure 5A). Similarly plasma IL-8 also increased significantly in both placebo $(\mathrm{p}<0.001)$ and ascorbic acid $(\mathrm{p}<0.001)$ groups but again there was no difference between the groups (Figure 5B).

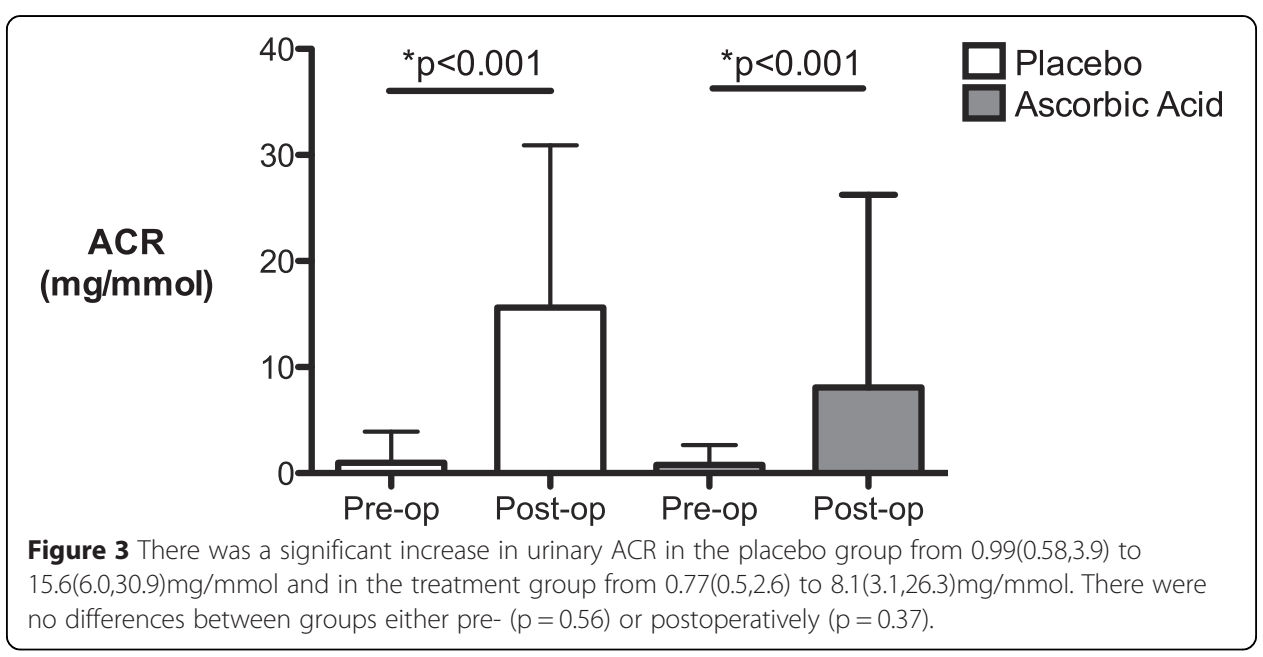




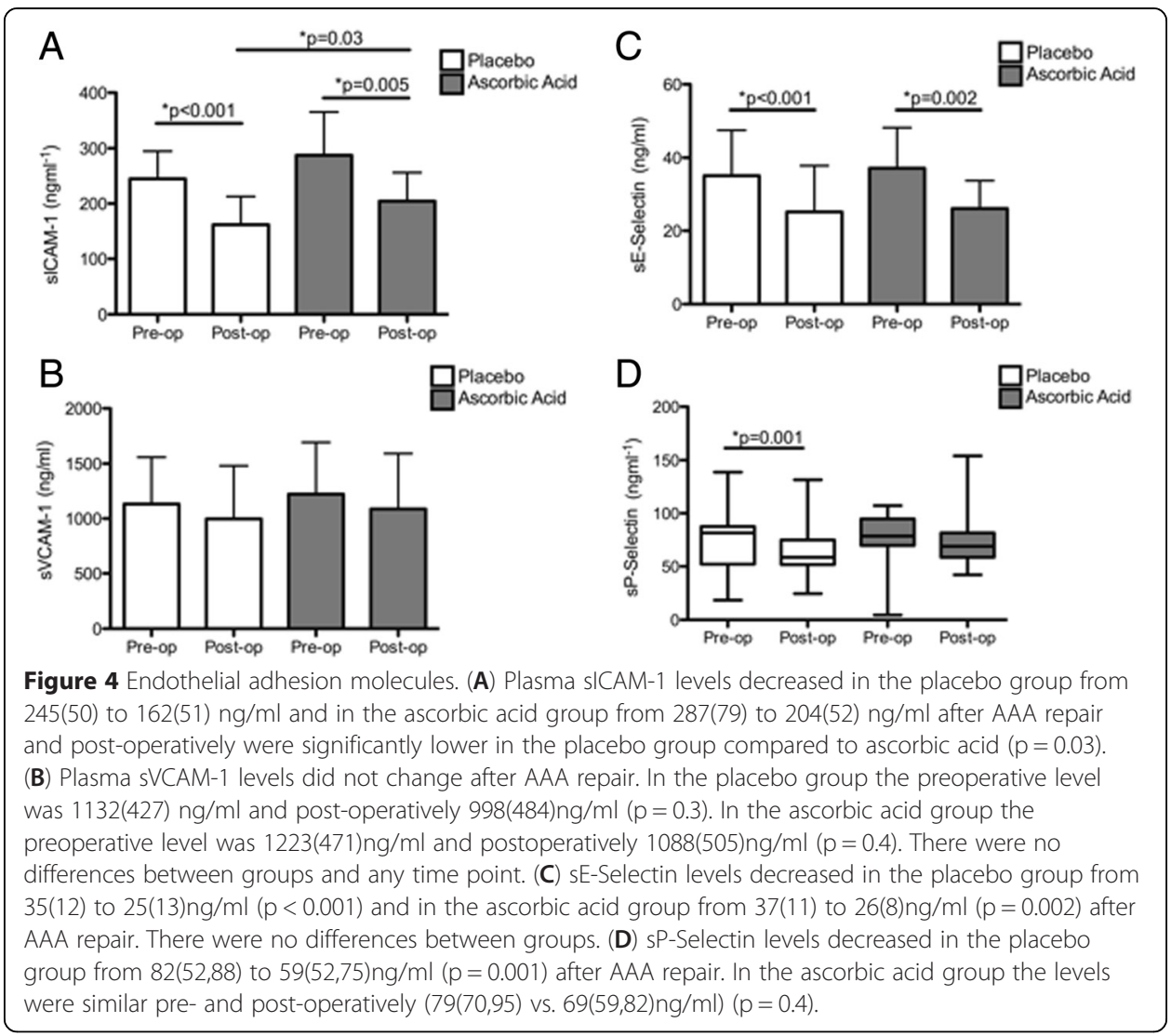

EBC $\mathrm{pH}$ decreased in both the placebo $(\mathrm{p}=0.008)$ and ascorbic acid $(\mathrm{p}=0.002)$ groups post-operatively although there was no difference between the groups (Figure 6). Systemic arterial $\mathrm{pH}$ also decreased in both the placebo $(\mathrm{p}<0.001)$ and ascorbic acid $(\mathrm{p}=0.005)$ groups post-operatively although there was no difference between the groups (Table 2). There was no significant correlation in the change in systemic arterial $\mathrm{pH}$ and $\mathrm{EBC} \mathrm{pH}$ in either the placebo $\left(\mathrm{p}=0.52, \mathrm{r}^{2}=0.03\right)$ or ascorbic acid $\left(\mathrm{p}=0.23, \mathrm{r}^{2}=0.13\right)$ groups.

\section{Effects of ascorbic acid on systemic oxidative stress}

Plasma lipid hydroperoxides decreased in the placebo group $(p=0.002)$ but not in the ascorbic acid group $(\mathrm{p}=0.38)$. Furthermore post-operative lipid hydroperoxides were significantly higher in the ascorbic acid group ( $\mathrm{p}<0.001$, Figure 7A). Plasma 8-isoprostane was similar pre and post open AAA repair in both groups and there was no difference between groups (Figure 7B).

\section{Effects of ascorbic acid on pulmonary function and clinical outcomes}

The $\mathrm{PaO}_{2}: \mathrm{FiO}_{2}$ ratio fell significantly in both placebo $(\mathrm{p}=0.002)$ and ascorbic acid $(\mathrm{p}<0.001)$ groups although there was no difference between groups (Figure 8).

Post-operative infections were diagnosed in $3(17 \%)$ of the placebo group and in 2 $(8 \%)$ of the ascorbate group $(\mathrm{p}=0.62)$. Only 3 patients in each group required postoperative invasive ventilation and the duration of ventilation was similar between groups $(\mathrm{p}=0.77)$. The duration of stay in critical care was similar between the placebo 

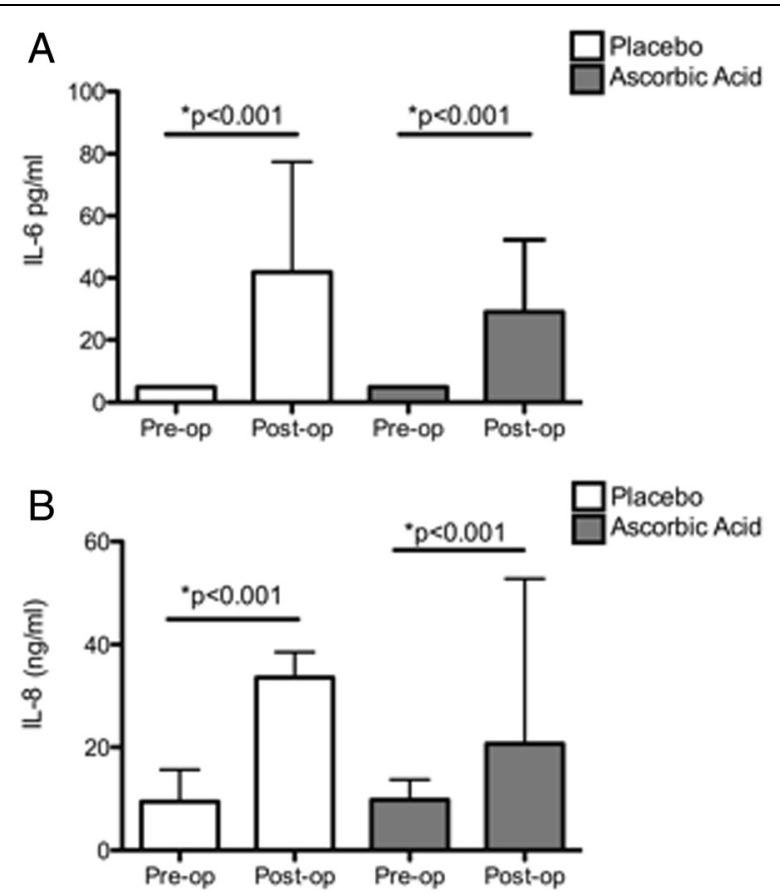

Figure 5 (A) IL-6 increased in the placebo group from 4.9(4.9,5.0) to 41.8(33.5,77.4) pg/ml $(p<0.001)$ and in the ascorbic acid group from $4.9(4.9,5.0)$ to $29.0(13.3,52.3) \mathrm{pg} / \mathrm{ml}(\mathrm{p}<0.001)$ after AAA repair. (B) IL-8 levels increased in the placebo group from $9.5(5.6,15.6)$ to $33.6(18.3,38.6) \mathrm{pg} / \mathrm{ml}(\mathrm{p}<0.001)$ and in the ascorbic acid group from $9.8(3.7,13.7)$ to $20.7(14.8,52.9) \mathrm{pg} / \mathrm{ml}(\mathrm{p}<0.001)$ after open AAA repair. There was no difference between groups at any time-point for either of these inflammatory mediators.

and ascorbic acid groups (2.9 (3.5) days versus 2.3 (3.2) days, $\mathrm{p}=0.64)$. Similarly there was no difference in hospital stay (10.2 (4.8) versus $8.8(2.6)$ days, $\mathrm{p}=0.37)$. There was one post-operative fatality in the placebo group. No serious adverse reactions related to the study drug occurred.

\section{Discussion}

We have found that open AAA repair caused significant changes in markers of systemic endothelial dysfunction as well as an increase in systemic and pulmonary inflammation, and a reduction in a marker of pulmonary function. However ascorbic acid therapy did not attenuate changes in these biomarkers following open AAA repair.

Our findings are in keeping with previous data showing increased urinary ACR and inflammation and with a decrease in $\mathrm{PaO}_{2}: \mathrm{FiO}_{2}$ ratio following open AAA repair $[12,38]$. In contrast to these findings however we did not see an increased serum CRP or increased plasma vWF. An increasing proportion of participants now receive treatment for co-morbid conditions such as statins. Statins have anti-inflammatory effects $[28,39]$ and may modulate endothelial function modifying responses to open AAA surgery. We found no increase in pulmonary dead space fraction. It is possible that the injury was not sufficient to induce pulmonary endothelial dysfunction or that the time to post operative assessment was of insufficient duration. As part of the standardized anaesthetic protocol, maintenance was with sevoflurane which has been shown to protect the endothelium from ischaemia-reperfusion injury [40] and might have further attenuated any potential pulmonary endothelial injury. 


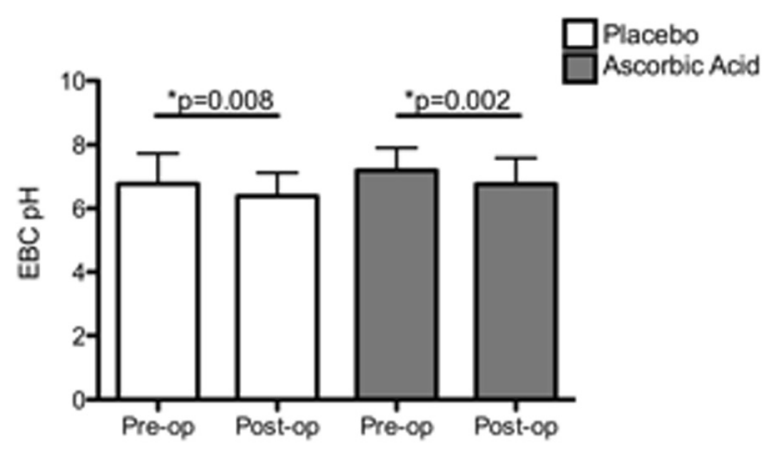

Figure $6 \mathrm{EBC} p \mathrm{pH}$ decreased in the placebo group from 7.38(0.04) to 7.32(0.08) $(p=0.008)$ after open AAA repair. In the ascorbic acid group the EBC $\mathrm{pH}$ fell from $7.40(0.05)$ to $7.29(0.06)(p=0.002)$ post-operatively. The pre- and post-operative levels were similar between groups (Table 2).

The fall in $\mathrm{EBC} \mathrm{pH}$ as a marker of alveolar neutrophilic inflammation was an interesting finding. This was associated with a decrease in the $\mathrm{PaO}_{2}: \mathrm{FiO}_{2}$ ratio. The fall in $\mathrm{EBC} \mathrm{pH}$ in this study may reflect pulmonary inflammation given that there was no correlation found with this decrease and changes in systemic $\mathrm{pH}$.

Ischaemia-reperfusion injury has been used to provoke acute lung injury (ALI) in animal models [41]. The obligate ischaemia-reperfusion injury of open AAA repair is associated with post operative pulmonary dysfunction [42]. A recent observational study
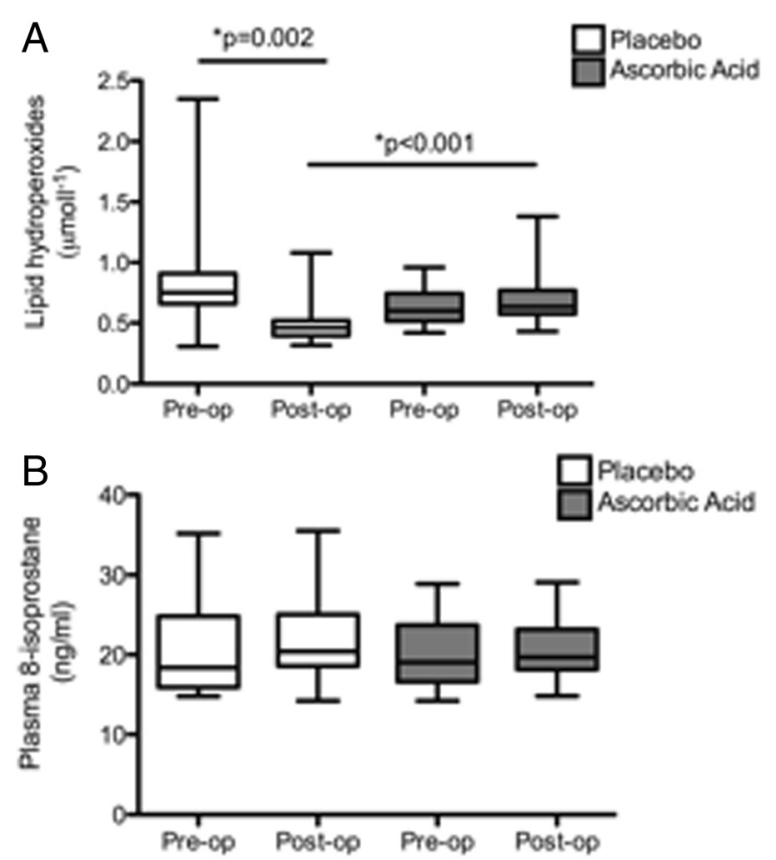

Figure 7 Oxidative stress markers. (A) Lipid hydroperoxide decreased in the placebo group from $0.8(0.7,0.9)$ to $0.5(0.4,0.5) \mu \mathrm{mol} / \mathrm{I}(\mathrm{p}=0.002)$ after AAA repair. In the ascorbic acid group the preoperative level $0.6(0.5,0.7) \mu \mathrm{mo} / \mathrm{I}$ did not change and postoperatively was $0.6(0.6,0.8) \mu \mathrm{mol} / \mathrm{I}(p=0.4)$. Post-operatively lipid hydroperoxide levels were significantly higher in the ascorbic acid group compared with placebo $(p<0.001)$. (B) Plasma 8-isoprostane levels did not change after AAA repair in either group and there was no difference between groups at any time-point. In the placebo group the preoperative level $18.4(15.9,24.8) \mathrm{ng} / \mathrm{ml}$ did not change after AAA repair being $20.4(18.6,25.1) \mathrm{ng} / \mathrm{ml}(\mathrm{p}=0.3)$. In the ascorbic acid group the preoperative level $19.1(16.6,23.7) \mathrm{ng} / \mathrm{ml}$ did not change and postoperatively was $19.7(18.2,23.2) \mathrm{ng} / \mathrm{ml}(p=0.6)$. There was no difference between groups at any time point. 


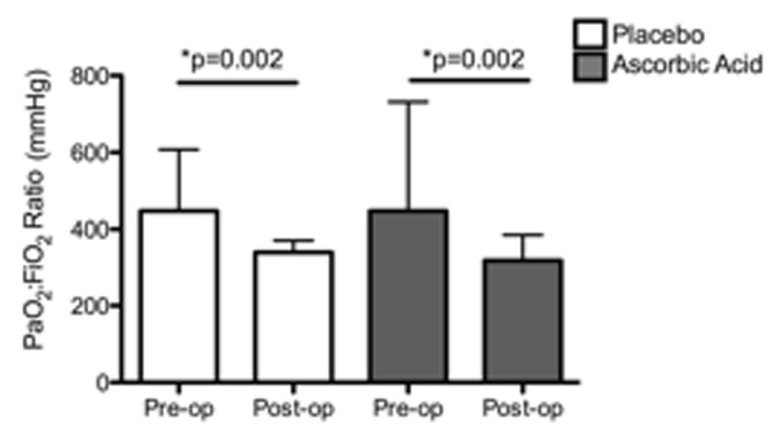

Figure 8 The PaO2:FiO2 ratio decreased in the placebo group from $447(398,608)$ to $340(212,370) \mathrm{mmHg}$ $(p=0.002)$ and in the ascorbic acid group from $447(349,733)$ to $319(245,385) \mathrm{mmHg}(p=0.002)$ after AAA repair. There were no differences demonstrated between groups (Table 2).

found that post-operative respiratory failure was associated with increased mortality [43]. Reflecting findings in ALI, we have shown open AAA repair is associated with local alveolar inflammation as well as systemic endothelial dysfunction and inflammation. Elevated plasma IL-6 and -8 levels are predictive of outcome in patients with ALI [44]. As a marker of systemic vascular permeability, urinary ACR has been shown to have an inverse relationship with $\mathrm{PaO}_{2}: \mathrm{FiO}_{2}$ ratio in a cohort of trauma patients [45]. These findings support the use of open AAA repair as a human model of ALI induced by systemic inflammation. However, in the present study mediators implicated in ALI such as vWF [11] were not elevated. It is possible that endothelial injury was not caused to a measurable level. In a murine model of ALI the administration of parenteral ascorbic acid (200 mg/ ml) 30 minutes after a septic insult attenuated the inflammatory response and was associated with improved survival, pulmonary function and coagulation [21]. In this study Fisher and colleagues suggested that the protective effects of ascorbic acid are due to its pleotropic actions on multiple pathways and it is possible in the current study, a lack of benefit may be related to the limitations in biomarkers used.

We investigated a single $2 \mathrm{~g}$ bolus of intravenous ascorbic acid following induction of anaesthesia in this study. This dose was informed by previous research where pretreatment with $2 \mathrm{~g}$ ascorbic acid was found to modulate the adverse haemodynamic effects of experimentally induced hyperglycaemia [46]. In addition ascorbic acid (2 g) has been shown to prevent hyperglycaemia-induced endothelial dysfunction in healthy human volunteers [47].

In the present study a decrease in plasma adhesion molecules was found. Haemodilution as part of intra-operative management could be potential mechanism for the reduction in soluble adhesion molecules as well as the lack of increase in serum hsCRP. However, as plasma IL-6 and IL-8 both increased, haemodilution is less likely. Comorbid treatment may also have influenced adhesion molecules expression. Both statins and $\beta$ blockers may modify adhesion molecules expression. Human coronary endothelial cells treated with nebivolol in vitro have a decrease in VCAM-1, ICAM-1, E- and P-Selectin expression [48]. Interestingly in another study of open AAA repair there was a non-significant fall in both ICAM-1 and VCAM-1 [49]. This has been mirrored in an in vitro study of human aortic endothelial cells which showed exposure of these cells to hypoxia and subsequent reoxygenation did not upregulate surface expression or shedding of adhesion molecules [50]. 
There was no increase in markers of oxidative stress in the placebo group unlike in other studies. Prosaglandin $F_{2 \alpha}$ is increased both on hospital arrival and during the perioperative period in patients with ruptured AAA repair [51]. Malondialdehyde, another marker of oxidative damage was increased at one and 24 hours post open AAA repair [52]. In a recent small observational study derivatives of reactive oxygen metabolites were used to define post-operative oxidative stress in patients undergoing aortic surgery. This showed that in those having open AAA repair this marker was no different at 24 hours after surgery, but was significantly elevated 1 week later [53]. This study had an earlier sampling time, older cohort of patients and aortic clamp times contributing to the different data between studies.

Ascorbic acid did not improve markers of endothelial function or attenuate the inflammatory response markers in this study. In previous research pretreatment with $2000 \mathrm{mg}$ parenteral ascorbic acid prevented arterial stiffness secondary to induced hyperglycaemia in healthy male volunteers [23]. In a study of 37 critically ill patients with burns the use of high dose ascorbic acid $(66 \mathrm{mg} / \mathrm{kg} / \mathrm{hr})$ for 24 hours reduced fluid requirements, wound oedema, and severity of pulmonary dysfunction [25]. In a doubleblind randomized placebo-controlled trial of 216 critically ill patients, enteral ascorbic acid (500 mg/day) and tocopherol (400 IU/day) was associated with a decrease in 8isoprostane. The anti-oxidant treated group had improved 28-day mortality and more ventilator free days [54]. We found lipid hydroperoxides were increased with ascorbic acid. This increase in lipid peroxides was not seen in plasma 8-isoprostanes, another measure of oxidative stress. Lipid hydroperoxides can be affected by dietary factors not accounted for in the current study. Isoprostane levels however, are not affected by diet [55] and may be a better measure of oxidative stress [56]. Previous studies utilizing the FOX assay have indicated its lack of specificity for hydroperoxides [57]. However, in keeping with our findings, Bailey at al found $2000 \mathrm{mg}$ ascorbic acid orally two hours before operation in patients undergoing major vascular surgery increased both lipid peroxides and plasma IL-6 [58]. Possible reasons for increased oxidative stress markers in this current study may relate to the timing of sampling and range of ischaemic times. It is possible that at the dose used in this study, ascorbic acid acted as a pro-oxidant with no beneficial effects on either the endothelium or measured mediators of inflammation.

There are numerous limitations in this study. The patient cohort was small increasing the risk of a type 2 error. Within the participants neither aneurysm size or anatomical location were described. Duration of aortic clamping was recorded but the position was not noted. Although the surgical approach and anaesthetic technique was standardized the quantities of transfused blood products and fluids were not compared. Similarly the need for cardiovascular support was not quantified. These confounding factors may have had a consequence on the resultant endothelial injury. Having taken measurements using a limited number of biomarkers of organ dysfunction up to only 4 hours following aortic clamping may increase the risk of a type 1 error.

\section{Conclusion}

In conclusion, open AAA repair caused increased markers of systemic endothelial dysfunction and inflammation with an associated fall in oxygenation. These findings 
support the use of open AAA repair as a human model of ALI induced by systemic inflammation. Ascorbic acid administration did not improve the measured biomarkers and limited functional parameters observed.

\section{Competing interests}

MJD has received payments from Otsuka Pharmaceuticals for lectures. MS has financial interest in AstraZeneca DFM DWH, BAM no interests to declare. DFM and CMO'K have received consultancy fees from Orion, GlaxoSmithKline and AstraZeneca and have research funding from GlaxoSmithKline for Acute Lung Injury. ISY has received funding for lectures from Astra Zeneca, Merck and Roche and is a member of the advisory committee on nutrition to Dept of Health UK

\section{Authors' contributions}

MJD, BAM, CMO'K, DFM, DWH: Study design and conduct. MJD, ISY: Laboratory analyses. MJD, BAM, DFM: Manuscript authors. MJD, MS: Data analyses. All authors read and approved the final manuscript.

\section{Acknowledgements}

We wish to acknowledge those patients and their families who agreed to participate in the study.

\section{Funding}

This study was funded by a research grant from the British Journal of Anaesthesia / RCoA. Equipment was provided by a grant from the Vascular Anaesthetic Society of Great Britain and Ireland. The research team also received a small grant from Revive, the Regional Intensive Care Unit Charity.

\section{Attribution of Work}

Centre for Infection and Immunity, The Queen's University Belfast

Regional Intensive Care Unit, Royal Victoria Hospital, Belfast

\section{Summary statement}

A prospective randomized controlled trial of ascorbic acid in open AAA repair demonstrated pulmonary and systemic endothelial injury with increased systemic inflammation postoperatively. The administration of ascorbic acid did not attenuate biomarkers of endothelial damage.

\section{Author details}

${ }^{1}$ Regional Intensive Care Unit, Royal Victoria Hospital, Belfast, UK. ${ }^{2}$ Centre for Infection and Immunity, The Queen's University Belfast, First Floor, Health Sciences Building, 97 Lisburn Road, Belfast BT9 7BL, UK. ${ }^{3}$ Centre for Public Health, The Queen's University Belfast, Belfast, UK. ${ }^{4}$ Regional Vascular Surgery Unit, Royal Victoria Hospital, Belfast, UK.

Received: 9 June 2014 Accepted: 24 March 2015

Published online: 01 July 2015

\section{References}

1. Bown M, Nicholson ML, Bell PRF, Sayers RD (2001) Cytokines and inflammatory pathways in the pathogenesis of multiple organ failure following abdominal aortic aneurysm repair. Eur J Vasc Endovasc Surg 22:485-495

2. McCord J (1985) Oxygen-derived free radicals in postischemic tissue injury. N Engl J Med 312:159-163

3. Edrees WK, Lau LL, Young IS, Smye MG, Gardiner KR, Lee B, Hannon RJ, Soong CV (2003) The effect of lower limb ischaemia-reperfusion on intestinal permeability and the systemic inflammatory response. Eur J Vasc Endovasc Surg 25:330-335

4. Morrow J, Roberts $L$ (2002) The isoprostanes their role as an index of oxidant stress status in human pulmonary disease. Am J Respir Crit Care Med 166:S25-S30

5. Entman M, Youker K, Shappell S (1990) Neutrophil adherence to isolated adult canine myocytes. Evidence for a CD18-dependent mechanism. J Clin Invest 85:1497-1506

6. Shreeniwas R, Koga S, Karakurum M (1992) Hypoxia mediated induction of endothelial cell interleukin-1 alpha. An autocrine mechanism promoting expression of leukocyte adhesion molecules on the vessel surface J Clin Invest 90:2333-2339

7. Karakurum M, Shreeniwas R, Chen J, Pinsky D, Yan SD, Anderson M, Sunouchi K, Major J, Hamilton T, Kuwabara K, Rot A, Nowygrod R, Stern D (1994) Hypoxic Induction of Interleukin-8 Gene Expression in Human Endothelial Cells. J Clin Invest 93:1564-1570

8. Malik A, Sultan S, Turner S (2007) Urinary albumin excretion is associated with impaired flow- and nitroglycerinmediated brachial artery dilatation in hypertensive adults. J Hum Hypertens 21:231-8

9. Pedrinelli R, Dell'Omo G, Penno G (2001) Non-diabetic microalbuminuria, endothelial dysfunction and cardiovascular disease. Vasc Med 6:257-64

10. Norwood M, Sayers R (2005) Urinary Albumin:Creatinine Ratio (ACR) and the Prediction of Postoperative Complications After Abdominal Aortic Aneurysm Repair. Eur J Vasc Endovasc Surg 30:353-358

11. Ware LB, Eisner MD, Thompson BT, Parsons PE, Matthay MA (2004) Significance of von willebrand factor in septic and non-septic patients with acute lung injury. Am J Resp Crit Care Med 170(7):766-772

12. Rittoo D (2005) Randomized study comparing the effects of hydroxyethyl starch solution with gelofusine on activated endothelium and the systemic AAinflammatory response following aortic aneurysm repair. Eur J Vasc Endovasc Surg 30(5):520-524

13. Smith FC, Gosling P, Sanghera K, Green MA, Paterson IS, Shearman CP (1994) Microproteinuria predicts the severity of systemic effects of reperfusion injury following infrarenal aortic aneurysm surgery. Ann Vasc Surg 8:1-5 
14. Duffy MJ, Mullan BA, Craig TR, Shyamsundar M, MacSweeney RE, Thompson G, Stevenson M, McAuley DF (2011) Impaired endothelium-dependent vasodilatation is a novel predictor of mortality in intensive care. Crit Care Med 39(4):629-635

15. Nuckton TJ, Alonso JA, Kallet RH, Daniel BM, Pittet JF, Eisner MD, Matthay MA (2002) Pulmonary dead-space fraction as a risk factor for death in the acute respiratory distress syndrome. N Engl J Med 346:1281-1286

16. Wilson J (2009) Mechanism of action of vitamin C in sepsis: Ascorbate modulates redox signaling in endothelium. Biofactors 35(1):5-13

17. Frei B, England L, Ames B (1989) Ascorbate is an outstanding antioxidant in human blood plasma. Proc Natl Acad Sci U S A 86:6377-6381

18. Pietri S, Seguin JR, d'Arbigny P, Culcasi M (1994) Ascorbyl free radical: a noninvasive marker of oxidative stress in human open-heart surgery. Free Radic Biol Med 16:523-528

19. Lassnigg A, Punz A, Barker R, Keznicki P, Manhart N, Roth E, Hiesmayr M (2003) Influence of intravenous vitamin E supplementation in cardiac surgery on oxidative stress: a double-blinded, randomized, controlled study. Br J Anaesth 90:148-154

20. Fain O, Paries J, Jacquart B, LeMoel G, Kettaneh A, Stirnemann J, Heron C, Stibon M, Taleb C, Letellier E, Betari B, Gattegno L, Thomas M (2003) Hypovitaminosis C in hospitalized patients. Eur J Intern Med 14:419-425

21. Fisher BJ, Krausauskas D, Martin EJ, Farkas D, Wegelin JA, Brophy D, Ward KR, Voelkel NF, Fowler AA III, Natarajan R (2012) Mechanisms of attenuation of abdominal sepsis induced acute lung injury by ascorbic acid. Am J Physiol Lung Cell Mol Physiol 303:L20-L32

22. Ware L, Matthay M (2000) The acute respiratory distress syndrome. New Eng J Med 342(18):1334-1349

23. Mullan BA, Ennis CN, Fee HJ, Young IS, McCance DR (2004) Protective effects of ascorbic acid on arterial haemodynamics during acute hyperglycaemia. Am J Physiol Heart Circ Physiol 287:H1262-68

24. Marshall J (2008) Sepsis: rethinking the approach to clinical research. J Leukoc Biol 83:471-482

25. Tanaka H, Matsuda T, Miyagantani Y, Yukioka T, Maysuda H, Shimazaki S (2000) Reduction of resuscitation fluid volumes in severely burned patients using ascorbic acid administration: a randomized, prospective study. Arch Surg 135:326-331

26. Wu F, Tyml K, Wilson J (2008) iNOS expression requires NADPH oxidase-dependent redox signaling in microvascular endothelial cells. J Cell Physiol 217:207-214

27. Landmesser U, Dikalov S, Price SR, McCann L, Fukai T, Holland SM, Mitch WE, Harrison DG (2003) Oxidation of tetrahydrobiopterin leads to uncoupling of endothelial cell nitric oxide synthase in hypertension. J Clin Invest 111:1201-1209

28. Shyamsundar M, McKeown STW, O'Kane CM, Craig TR, Brown V, Thickett DR, Matthay MA, Taggart CC, Backman JT, Elborn JS, McAuley DF (2009) Simvastatin Decreases Lipopolysaccharide-induced Pulmonary Inflammation in Healthy Volunteers. Am J Respir Crit Care Med 179:1107-1114

29. Jiang Z, Hunt J, Wolff S (1992) Ferrous ion oxidation in the presence of xylenol orange for detection of lipid hydroperoxide in low density lipoprotein. Anal Biochem 202(2):382-389

30. Vuillemier J (1989) Fluorometric assay of vitamin C in biological materials using a centrifugal analyser with fluorescence attachment. J Micronut Analysis 5:25-34

31. Junge W, Wilke B, Halabi A, Klein G (2004) Determination of reference intervals for serum creatinine, creatinine and creatinine clearance with an enzymatic and a modified Jaffe method. Clin Chim Acta 344:137-148

32. Wilkinson IB, MacCallum H, Cockcroft JR, Webb DJ (1998) Pulse wave analysis and arterial stiffness. J Cardiovasc Pharmacol 32(Suppl 3):S33-S37

33. Wilkinson IB, Hall IR, MacCallum H, MacKenzie IS, McEniery CM, van der Arend BJ, Shu Y, MacKay LS, Webb DJ, Cockroft JR (2002) Pulse-wave analysis:clinical evaluation of a noninvasive, widely applicable method for assessing endothelial function. Arterioscler Thromb Vasc Biol 22:147-152

34. Lind L, Petterson K, Johansson K (2003) Analysis of endothelium dependent vasodilation by use of the radial artery pulse wave obtained by applanation tonometry. Clin Physiol Func Im 23:50-57

35. Cepkova M, Kapur V, Ren X, Quinn T, Zhuo H, Foster E, Liu KD, Matthay MA (2007) Pulmonary dead space fraction and pulmonary artery systolic pressure as early predictors of clinical outcome in acute lung injury. Chest 132:836-842

36. Kallet RH, Daniel BM, Garcia O, Matthay MA (2005) Accuracy of physiologic dead space measurements in patients with acute respiratory distress syndrome using volumetric capnography: comparison with the metabolic monitor method. Respir Care 50(4):462-467

37. Moloney ED, Mumby SE, Gajdocsi R, Cranshaw JH, Kharitonov SA, Quinlan GJ, Griffiths MJ (2004) Exhaled breath condensate detects markers of pulmonary inflammation after cardiothoracic surgery. Am J Respir Crit Care Med 169:64-69

38. Rittoo D, Gosling P, Burnley S (2004) Randomized study comparing the effects of hydroxyethyl starch solution with gelofusine on pulmonary function in patients undergoing abdominal aortic aneurysm surgery. $\mathrm{Br} J$ Anaesth 92:61-66

39. Craig TR, Duffy MJ, Shyamsundar M, McDowell C, O'Kane CM, Elborn JS, McAuley DF (2011) A randomized clinica trial of hydroxymethylglutaryl-coenzyme A reductase inhibition for acute lung injury (The HARP Study). Am J Resp Crit Care Med 183(5):620-626

40. Annecke T, Chappell D, Chen C, Jacob M, Welsch U, Sommerhoff CP, Rehm M, Conzen PF, Becker BF (2010) Sevoflurane preserves the endothelial glycocalyx against ischaemia-reperfusion injury. Br J Anaesth 104(4):414-421

41. Matute-Bello G, Frevert G, Martin T (2008) Animal models of acute lung injury. Am J Physiol Lung Cell Mol Physiol 295(3):L379-L399

42. Pararajasingam R, Nicholson ML, Bell PRF, Sayers RD (1999) Non-cardiogenic pulmonary oedema in vascular surgery. Eur J Vasc Endovasc Surg 17:93-105

43. Nathan DP, Brinster CJ, Jackson BM, Wang GJ, Carpenter JP, Fairman RM, Woo EY (2011) Predictors of decreased short- and long-term survival following open abdominal aortic aneurysm repair in a large contemporary series. J Vasc Surg 54(5):1237-43 
44. Meduri GU, Healdey S, Kohler G, Stentz F, Tolley E, Umberger R, Leeper R (1995) Persistent elevation of inflammatory cytokines predicts a poor outcome in ARDS. Chest 107:1062-1073

45. Gosling P, Sanghera K, Dickson G (1994) Generalized vascular permeability and pulmonary function in patients following serious trauma. J Trauma 36:477-81

46. Mullan BA, Ennis CN, Fee HJP, Young IS, McCance DR (2005) Pretreatment with intravenous ascorbic acid preserves endothelial function during acute hyperglycaemia. Clin Exp Pharmacol Physiol 32(5-6):340-345

47. Mullan BA, Ennis CN, Fee HJP, Young IS, McCance DR (2004) Protective effects of ascorbic acid on arterial hemodynamics during acute hyperglycemia. Am J Physiol Heart Circ Physiol 287:1262-1268

48. Wolf SC, Sauter G, Preyer M, Poerner T, Kempf VA, Risler T, Brehm BR (2007) Influence of nebivolol and metoprolol on inflammatory mediators in human coronary endothelial or smooth muscle cells. Effects on neointima formation after balloon denudation in carotid arteries of rats treated with nebivolol. Cell Physiol Biochem 19(1-4):129-136

49. Rehm M, Bruegger D, Christ F, Conzen P, Thiel M, Jacob M, Chappell D, Stoeckelhuber M, Welsch U, Reichart B, Peter K, Becker BF (2007) Shedding of the endothelial glycocalyx in patients undergoing major vascular surgery with global and regional ischemia. Circulation 116:1896-1906

50. Maurus CF, Schmidt D, Schneider MKG, Turina MI, Seebach JD, Zund G (2003) Hypoxia and reoxygenation do not upregulate adhesion molecules and natural killer cell adhesion on human endothelial cells in vitro. Eur J Cardiothorac Surg 23:976-983

51. Lindsay TF, Luo XP, Lehotay DC, Rubin BB, Anderson M, Walker PM, Romaschin A (1999) Ruptured abdominal aortic aneurysm, a "two-hit" ischemia/reperfusion injury: Evidence from an analysis of oxidative products. J Vasc Surg 30:219-228

52. Papalambros E, Sigala F, Georgopoulos S, Parakevas KI, Anreadou I, Menenakos X, Sigalas P, Papalambros AL, Vourliotakis G, Giannopoulos A, Bakoyiannis C, Bastounis C, Bastounis E (2007) Malondialdehyde as an indicator of oxidative stress during abdominal aortic aneurysm repair. Angiology 58(4):477-482

53. Kanaoka Y, Inagaki E, Hamanaka S, Masaki H, Tanemoto K (2010) Analysis of Reactive Oxygen Metabolites (ROMs) after Cardiovascular Surgery as a Marker of Oxidative Stress. Acta Med Okayama 64(5):323-330

54. Crimi E, Liguori A, Condorelli M, Cioffi M, Astuto M, Bontempo P, Pignalosa O, Vietri MT, Molinari AM, Sica V, Della Corte F, Napoli C (2004) The Beneficial Effects of Antioxidant Supplementation in Enteral Feeding in Critically III Patients: A Prospective, Randomized, Double-Blind, Placebo-Controlled Trial. Anesth Analg 99:857-863

55. Richelle M, Turini ME, Guidoux R, Tavazzi I, Metairon S, Fay LB (1999) Urinary isoprostane excretion is not confounded by the lipid content of the diet. FEBS Lett 459:259-262

56. Halliwell B, Whiteman M (2004) Measuring reactive species and oxidative damage in vivo and in cell culture: how should you do it and what do the results mean? Br J Pharmacol 142:231-255

57. Yin H, Porter N (2003) Specificity of the ferrous oxidation of xylenol orange assay: analysis of autoxidation products of cholesteryl arachidonate. Anal Biochem 313(2):319-326

58. Bailey DM, Raman S, McEneny J, Young IS, Parham KL, Hullin DA, Davies B, McKeeman G, McCord JM, Lewis MH (2006) Vitamin C prophylaxis promotes oxidative lipid damage during surgical ischemia-reperfusion. Free Radic Biol Med 40:591-600

\section{Submit your manuscript to a SpringerOpen ${ }^{\circ}$} journal and benefit from:

- Convenient online submission

- Rigorous peer review

- Immediate publication on acceptance

- Open access: articles freely available online

- High visibility within the field

- Retaining the copyright to your article 